\title{
Fast Performance Computing Model for Smart Distributed Power Systems
}

\author{
Umair Younas, B. Khan, S. M. Ali \\ Department of Electrical Engineering COMSATS Institute of Information Technology \\ 22060 Abbottabad, Pakistan \\ umair.ciitatd@gmail.com, bilalkhan@ciit.net.pk, hallianali@ciit.net.pk
}

Alfredo Vaccaro

Department of Engineering, University of Sannio

82100 Benevento, Italy

vaccaro@unisannio.it

\begin{abstract}
Plug-in Electric Vehicles (PEVs) are becoming the more prominent solution compared to fossil fuels cars technology due to its significant role in Greenhouse Gas (GHG) reduction, flexible storage, and ancillary service provision as a Distributed Generation (DG) resource in Vehicle to Grid (V2G) regulation mode. However, large-scale penetration of PEVs and growing demand of energy intensive Data Centers (DCs) brings undesirable higher load peaks in electricity demand hence, impose supply-demand imbalance and threaten the reliability of wholesale and retail power market. In order to overcome the aforementioned challenges, the proposed research considers smart Distributed Power System (DPS) comprising conventional sources, renewable energy, V2G regulation, and flexible storage energy resources. Moreover, price and incentive based Demand Response (DR) programs are implemented to sustain the balance between net demand and available generating resources in the DPS. In addition, we adapted a novel strategy to implement the computational intensive jobs of the proposed DPS model including incoming load profiles, V2G regulation, battery State of Charge (SOC) indication, and fast computation in decision based automated DR algorithm using Fast Performance Computing resources of DCs. In response, DPS provide economical and stable power to DCs under strict power quality constraints. Finally, the improved results are verified using case study of ISO California integrated with hybrid generation.
\end{abstract}

Keywords: Smart Distributed Power System, Plug-in Electric Vehicles (PEVs), Demand Response (DR), Data Centers, Renewable Energy

\section{Introduction}

Transport sector is one of the major contributor in rising energy demand, environmental pollution, GHG emissions, and fuel consumption as presented Figure 1. Likewise, growing trend towards internet

traffic, e-commerce, big data, increasing digital contents enlarged the workload and ultimately maximize the power consumption of DCs [1]. Besides the Residential, Commercial, and Industrial (RCI) load, 
combine PEVs fleet charging, and massive energy consumption of DCs brings higher load peaks in overall electricity demand.

This massive power demand increases the stress on power system hence, disturb the balance and reliability of power system. First, we proceed with the detailed description regarding impact and role of PEVs in power system. PEVs are recently the emerging paradigm that provide undeniable socio-economic benefits, Greenhouse Gas (GHG) reduction, and replace gasoline fuels dependency with electricity, without violating the consumer preferences [2]. Besides, PEVs have the potential to offer reliable performance, safety, versatility, energy storage, and bidirectional power flow operation within smart grid.

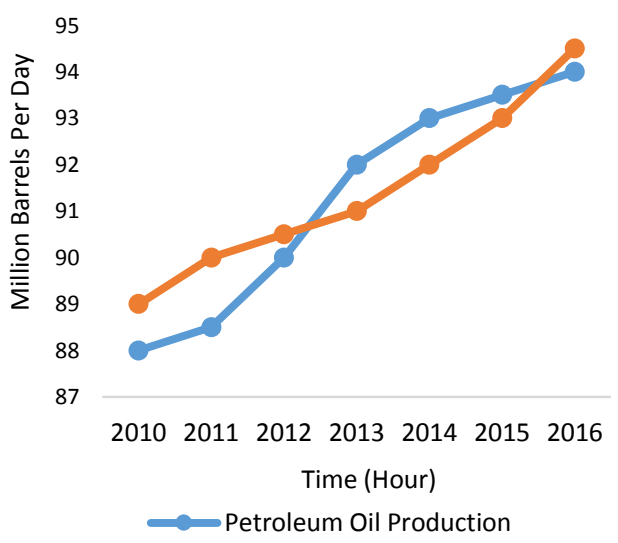

Figure 1: Global Growth in Petroleum Fuel

Despite the facilitating nature, large scale pervasion of PEVs increase peak load demand that further provoke considerable load impact on DPS if not properly managed and controlled [4]. However, optimal power consumption in charging of PEV's fleet become a challenge for modern researchers. Therefore, the authors in [5] presented gamming algorithm and real time load management approach [6] to optimize power consumption in PEV's charging. Likewise, optimization algorithms concerned with peak load demands of bulky EVs are presented in [7], and [8]. While, virtual power player based simulation technique is applied to accomplish DSM and V2G operations [9]. While, the authors in [10] incorporated DR scheduling policy for energy management of PEVs.

Secondly, another big challenge is the massive energy consumption of DCs including; Google, Microsoft, Amazon, Apple, and Facebook DCs. Just a single renowned Google DCs utilize more than 260 MW power, which can satisfy the power demand of 100,000 to 200,000 people. Likewise, Microsoft DC in Quincy, Washington utilize $48 \mathrm{MW}$ electricity that is enough to fulfil the power demand of 40,000 homes [11]. In 2013, the power consumption of DCs in U.S. was approximated 91 billion Kilowatt-hours. While, the future consumption is expected to reach 140 billion Kilo-Watt hours in 2020 and annually 100 million metric tons of carbon is created due to DC power utilization [12].

The literature review suggests that power system researchers are independently implementing various control schemes and optimization algorithms to minimize the distributed power consumption [13], [14].

Correspondingly, DC operators are individually using optimization strategies to minimize the operational cost and maximize the overall revenue. In the proposed work, we present a novel solution to utilize the online computing services of DC to solve the complex and computational intensive functions of DPS in smart grid like; a) fast computational response in DR services, b) fast information and communications flow between user and ISO, c) online large flexible volatile storage availability, and d) fast performance of optimization algorithm for selecting the appropriate available resource to meet the desired load demand. To the best of our knowledge, this holistic vision has not been explored in the power system domain. The main contributions of our work are: 
- Initially, we modelled fixed and controllable loads, and mix-generation resources connected to utility grid/ISO,

- The decision theory based multiobjective constrained optimization algorithm based on proposed model is implemented on ISO California, which constitutes about 71,823 MW generation capacity and have 28,000 MW peak load demand for a typical day in May 2016,

- We consider both PEVs and DCs load as prosumers, these are not only act as electric load but also provide ancillary services to the proposed DPS model,

- Grid supply and demand balance is sustained by using time and incentive based DR strategies (scheduling, shifting, and curtailment of load),

- Data center computational services are encouraged to accomplish fast computations to sustain the reliability of overall power system hence, fast and reliable services encourage customers to participate in DR programs.

The rest of the paper is organized as follows: Section II describe the multiobjective model of the proposed system design. In this section, we implemented decision based theory algorithm. Later, performance evaluation and the impact of ancillary services of data center on power system reliability and also revenue model of data center is analyzed in section III. Section IV concludes the paper with a brief summary and proposal enhancement of the current work.

\section{System Model Design}

In order to accommodate large-scale deployment of distributed RES and EVs penetration, unlike traditional deterministic optimization approaches, we are dealing with load/generation multi-criteria patterns hence, static scalar optimization is not optimal solution. However, to overcome the limitations, we formalize a constrained multi objective optimization problem that can be solved by any following non-linear programming techniques e.g. goal-attainment method, normal boundary injection, strength Pareto evolutionary algorithm, modified fuzzy based evolutionary algorithm. As, the abovementioned algorithms work perfectly when input parameters are determined.

However, in our work input conditions are uncertain hence, upgraded modified algorithms are required to incorporate data uncertainties in real time systems. The system architecture is demonstrated in Figure 2.

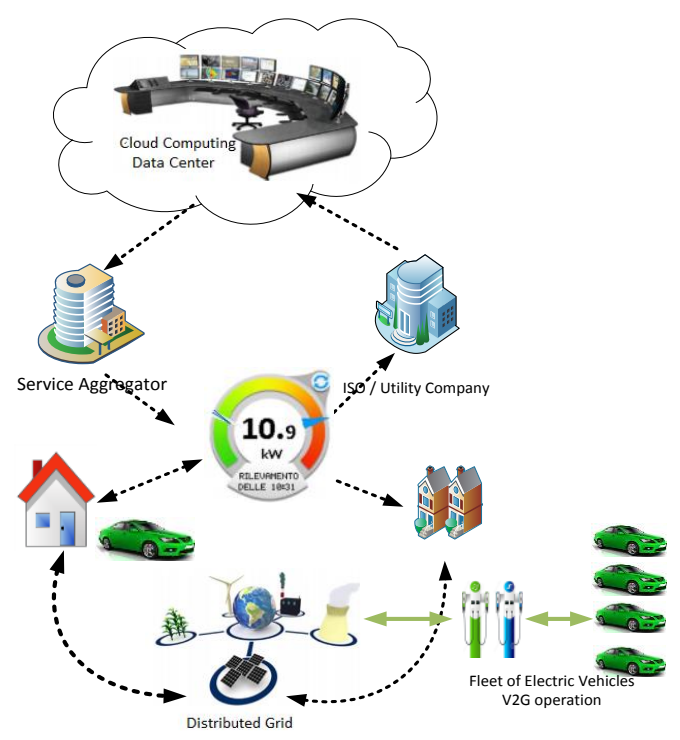

\section{Figure. 2: System Architecture of the} Proposed Model Design

In the proposed methodology, the desired objective is to maximize the revenue for both the utility/ISO and its customers. Customer's revenue is maximized by encouraging their participation in DR programs in order to reduce the power consumption and electric bills as presented in (1);

$$
\begin{aligned}
& \text { Revenue }=\sum_{t=1}^{T} P_{F}(t) \sum_{i}^{N} L_{i}(t)+ \\
& C_{\text {sel }} \sum_{t=1}^{T}\left(\sum_{i=1}^{N} L_{i}(t)-\bar{X}\right)^{2}
\end{aligned}
$$




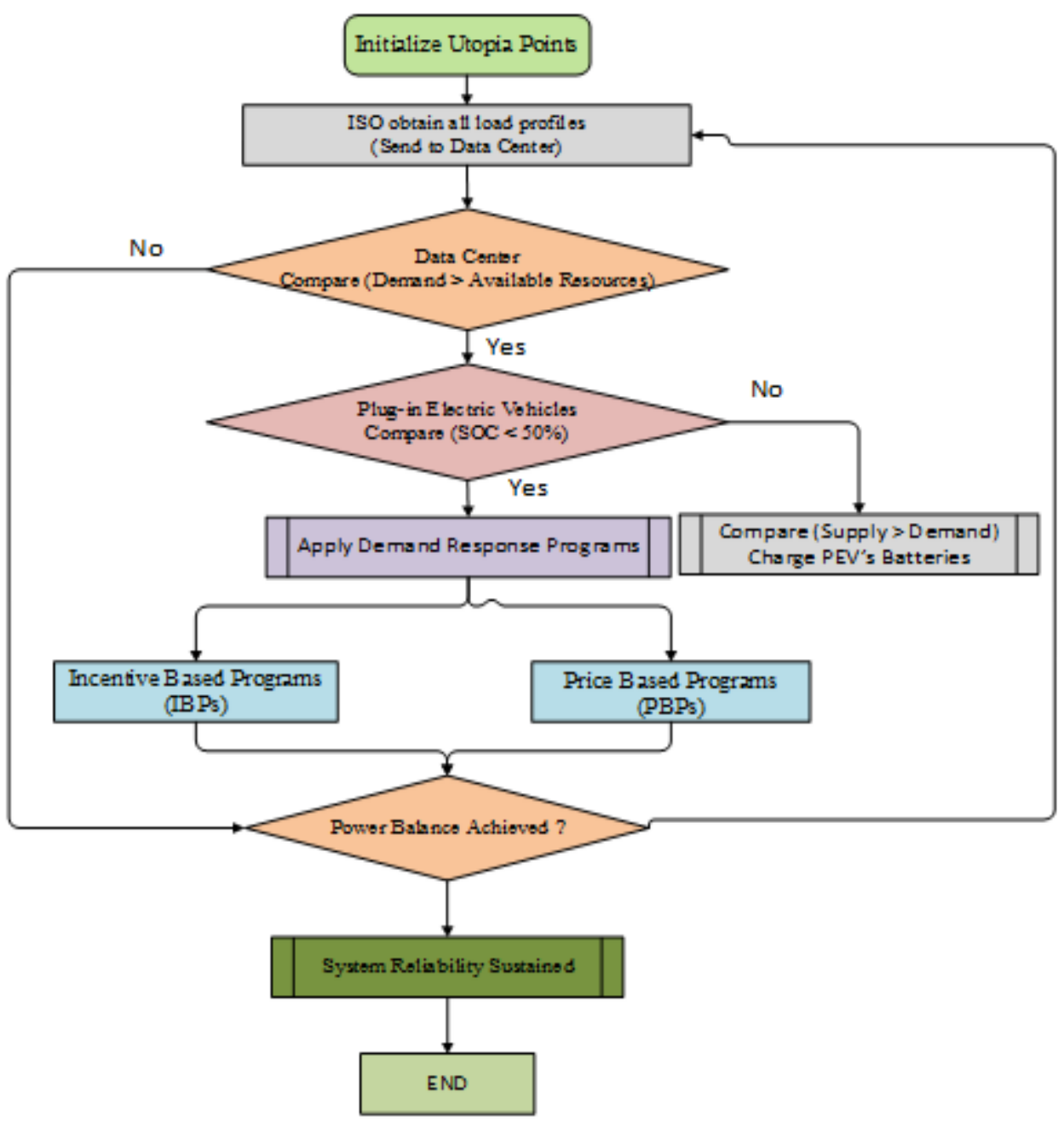

Figure. 3: Flow of Information between ISO and End-Customers

$L_{i}(t)=L_{i}^{F}(t)+L_{i}^{C}(t)+L_{i}^{E V}(t)+$

$L_{i}^{D}(t), \forall t$ and $i$

$$
\bar{X}=(1 / T) \sum_{t=1}^{T} \sum_{i=1}^{N} L_{i}(t)
$$

Where

$P_{F}(t)$ total power consumption by fixed load at time $t$;

$L_{i}(t)$ sum of all fixed and controllable loads at time $t$;

$\bar{X}$ average daily power consumption of user $i$ at time $t$
$L_{i}^{F}(t)$ total Fixed load of user $i$ at time $t$

$L_{i}^{C}(t)$ total controllable load of user $i$ at time $t$

$L_{i}^{E V}(t)$ total electric vehicle load of user $i$ at time $t$

$C_{\text {sel }} \quad$ C-select ranges [0:1] and describe dynamic of uncertain load

As, the above problem is comprised of two objective functions hence, the model can be re-written as; Revenue $=F 1+F 2$ where,

$$
F 1=\sum_{t=1}^{T} P_{F}(t) \sum_{i}^{N} L_{i}(t),
$$


$F 2=C_{s e l} \sum_{t=1}^{T}\left(\sum_{i=1}^{N} L_{i}(t)-\bar{X}\right)^{2}$,

The generalized representation of the proposed optimization problem is modelled in (4)

$$
\left\{\begin{array}{c}
\min _{x} \alpha_{F_{1}} \frac{F_{1}(x)}{\overline{F_{1}}}+\alpha_{F_{2}} \frac{F_{2}(x)}{\overline{F_{2}}} \\
\text { s.t. Battery } \operatorname{SOC}(0)=\text { Battery } \operatorname{SOC}(T), \\
P_{G R I D(t)}+P_{D R E S(t)} \geq P_{L_{i}(t)} \\
P_{L_{i}^{C}(t)}=0 \quad \forall t \in\left[T_{O N}, T_{O F F}\right] \\
P_{G R I D(t)^{\min }<P_{G R I D(t)}<P_{G R I D(t)^{\max }}} \\
\sum_{i=1}^{N} L B_{i}<\sum_{i=1}^{N} x_{i}<\sum_{i=1}^{N} U B_{i}
\end{array}\right.
$$

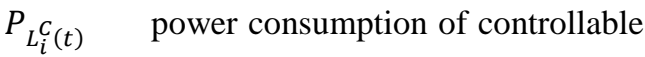
load of user $i$ at time $t$

$T_{O N} \quad$ Start time of the DR event duration

$T_{\text {OFF }} \quad$ Stop time for the DR event duration SOC (0) initial state of the charge of the storage battery $\operatorname{SOC}(T)$ final state of the charge of the storage battery

The proposed optimization model in (4) perform the revenue maximization in the presence of defined constraints. The optimized outputs contain DR time vector, dynamic load profiles, and available generation profiles to sustain DPS's reliability and balance between the demand and supply. The customers are able to schedule their electric load by participating time based and price based DR programs. In this way, customers maximize their revenue by reducing electric consumptions and bills. Likewise, when users minimize their consumption then high peaks will be flattened by valley filling and reliability of proposed DPS further improve. The flowchart of overall system is presented in Figure 3.

\section{Performance Evaluation}

\subsection{Case Study}

Worldwide, US is leading in sales of PEVs and particularly largest number of sales and registration of EVs are observed in
California State as presented in Figure 4 [15]. Therefore, we consider the case study of ISO California (CAISO) and collected it data for simulation purpose to analyze the impact of PEVs penetration on real power market. Total mixed installed generation capacity of ISO California energy sources is observed 71,823 MW while, the average peak load demand of May 2016 is 28,000 MW. The total 50,000 EVs are considered with annual mileage of 14,600 miles per day for each EV. In this work, the major contributions are based on large scale integration of RES and PEV's fleet. However, the ISO California is rich in RES and capable of dealing large number of EVs as demonstrated in Figure 5 hence, the state perfectly matches the proposed objective.

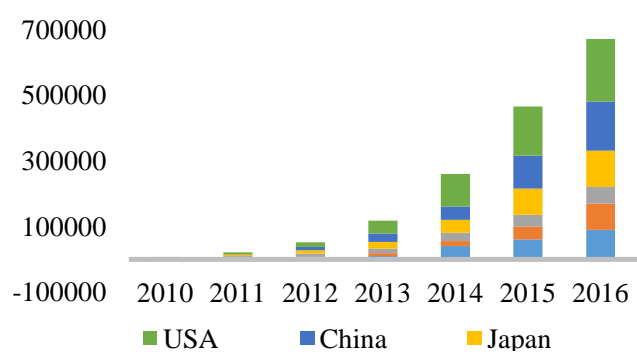

Figure. 4: Worldwide Sales of EVs from $2010-$ 2016 [15]

In California, more than $50 \%$ of PEVs sales are analyzed. As, large scale integration of PEVs desire large storage bank hence, PEV fleet can provide large storage to intermittent RES.Meanwhile, combine charging of fleet of PEVs also impose adverse effect on grid



Figure 5: Contribution of California State in Total US Sales of PEVs [15] 
overload, which is further elaborated in this paper.

\subsection{Supply and Demand of ISO California}

The total generation capacity and average load demand of ISO California is presented in Figure 6. While, net renewable generation capacity is illustrated in Figure 7. In this case, the grid is not overloaded because of large scale renewable potential of California. While, the state is perfectly suit to analyze the impact of PEVs charging on power system.

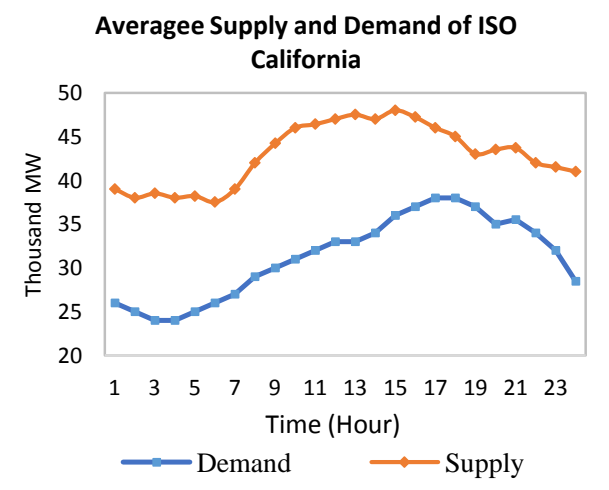

Figure. 4: Installed generation and average load demand of ISO California

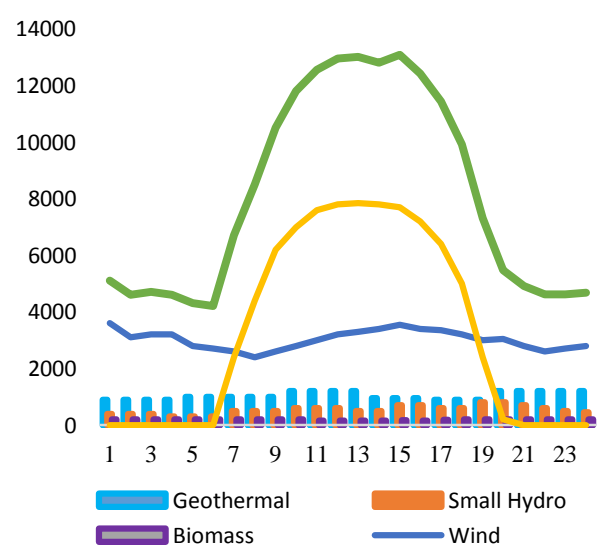

Figure. 5: Average RES Generation of ISO California in Typical Day May 2016

\subsection{Behavior of Uncontrolled EV charging on Load Profiles}

In this research, we introduced three charging scenarios of 50,000 EVs. However, the impact of each scenario is evaluated. In first scenario, the owners are interested to charge their EVs just after coming back to home from evening to late night. However, the combine charging of EVs at same time increase average residential load and brings undesirable higher peaks in overall load demand as shown in Figure 8. Furthermore, without any proper control the peak demand in residential load is almost doubled, which necessitate the increase in base load generation, increased power losses, and disturbed the sustainability and reliability of power system.

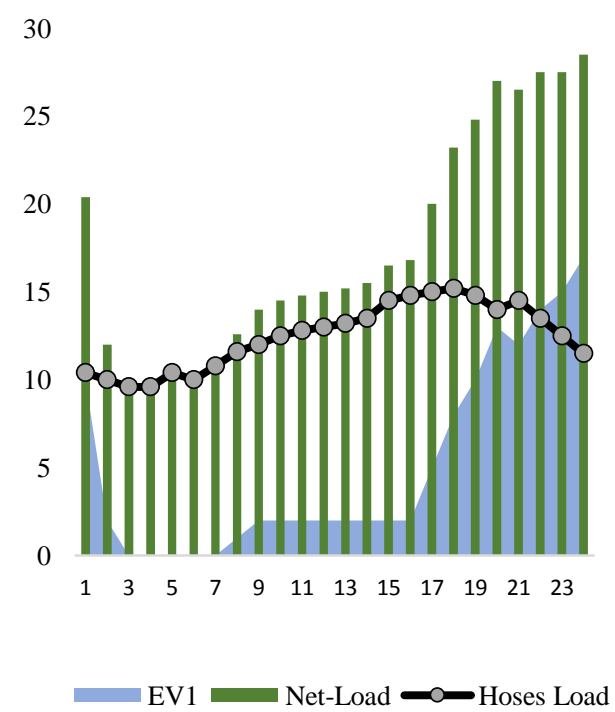

Figure. 6: Impact of Uncontrolled EVs on load demand in Scenario 01

While in the second scenario, the EV's owners are interested to charge their EVs in midnight hours when the prices are low. The impact of the charging of all EVs in these hours increase the load peaks for shorts hours Figure 9. In DR programs section, we overwhelmed these large peaks in load demand. 


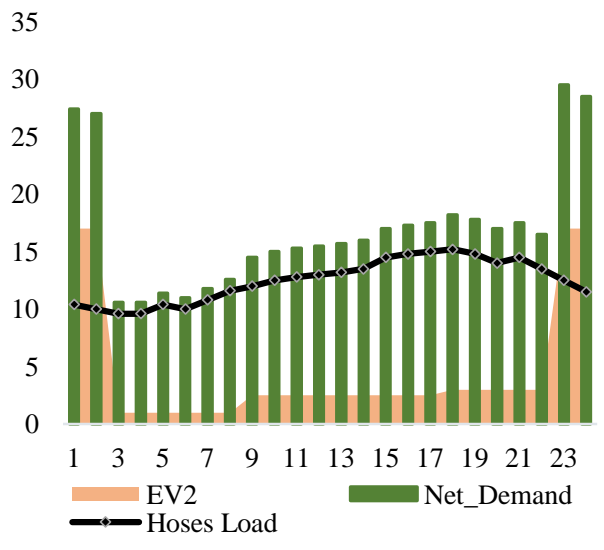

Figure. 7: Impact of Uncontrolled EVs on load demand in Scenario 2

PEV's owners are interested to charge their EVs in early morning hours. The combined charging effect is analyzed in Figure 10 while, next section proceeded with DR implementation to minimize this effect.

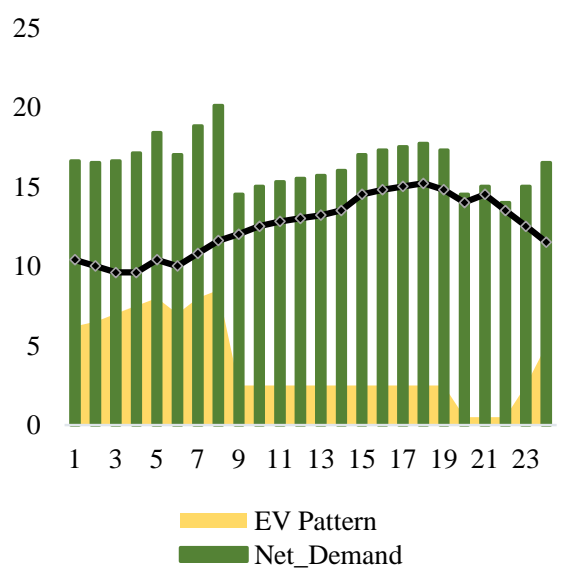

Figure. 8: Impact of Uncontrolled EVs on load demand in Scenario 3

\subsection{EV Charging Controlled using DR Programs}

DR is referred to the changes adopted by the customers in order to minimize the power consumption, when power system is jeopardized. PEVs are considered as the cheap promising DR resource to enhance power system reliability by minimizing the load fluctuations [16]. DR programs are basically divided into two main groups namely; a) Incentive based Programs (IBPs), and b) Price Based Programs (PBPs). PBPs are further categorized into Time of Use (TOU), Real Time Pricing (RTP), and Critical Peak Pricing (CPP). In PBPs, usually the electricity prices are more during higher peak demand and less during low peaks [17]. While, IBPs are offered to customers who show willingness to participate in DR programs through credit bill or discount rate. In this work, we incorporated PBPs to select the pricing policies for the incoming load profiles and IBPs are employed in order to get benefit from ancillary services of PEVs in V2G operating mode in higher peak hours. RTP DR strategy in scenario 01 verify load reduction and minimize spinning reserves and base load generation as presented in Figure 11.

In Figure 12, TOU pricing scheme is presented (Not to scale) while, comparative results with Figure 9 declare the huge reduction in peak load demand from 28 (unit MW) to 20 (unit MW). However, this is a big achievement and it allow the flexibility to accommodate more EVs.

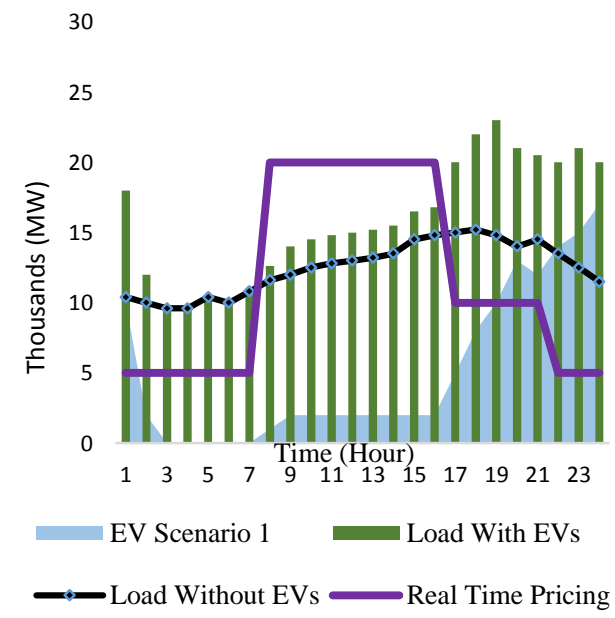

Figure. 9: Load Reduction Using RTP DR Scheme in Scenario 1 




Figure. 10: Load distribution using TOU pricing scheme in Scenario 2

Likewise, CPP DR event is called when the residential demand exceeded 20 thousand MW as illustrated in Figure 13. During CPP event, the prices are high so customers schedule or shift their load in peak hours and power system balance maintained due to load curtailment.

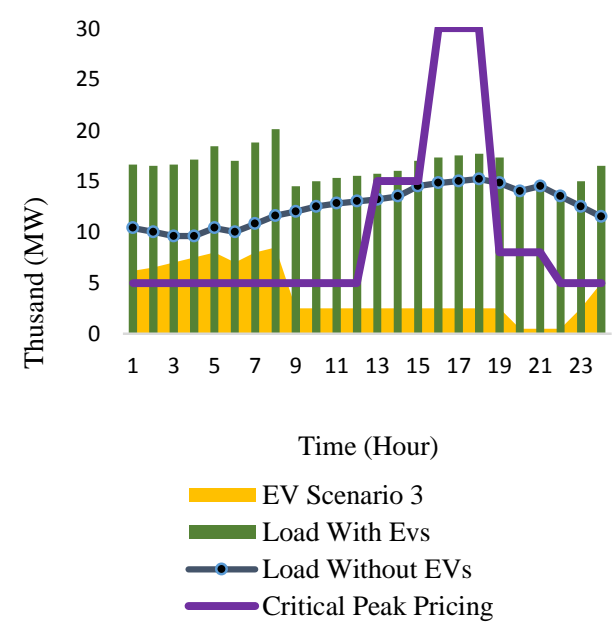

Figure. 11: Implementation of CPP DR Strategy in Scenario 3

\subsection{Ancillary Services of Green Data Centers}

In this work, the power hungry data centers are not only considered as an electrical load but also as an opportunity, because smart grid need fast computational infrastructure to visualize, monitor, manage, and control its applications. The holistic approach of this paper declares that the incorporation of fast parallel cloud computing services of data center enhance introduce the concept of virtualization in power system by providing; a) volatile flexible economical energy storage capacity, b) decrease the computational time of the tasks of proposed DPS, c) improve reliability of the system in term of service evaluations, and d) power system do not need to install large computational infrastructure, hence cost and revenue optimization is achieved in the proposed work, the ancillary services of cloud data center are highlighted in Figure 14. In this paper, we implemented decision based theory optimization algorithm to accomplish enhanced reliability of power system by using DR programs.

The simulation model is then evaluated through Amazon EC2 cloud in order to ensure the computational intelligence of the proposed model. In the presence of fast computing services of the data center the convergence and scheduling time of the DPS jobs/tasks is reduced and improved

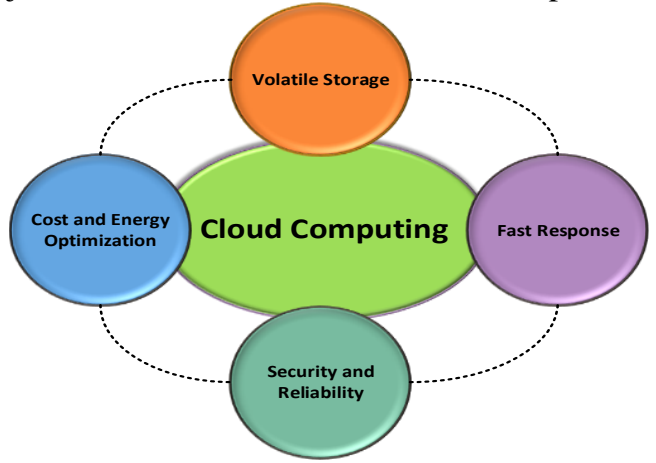

Figure.14: Cloud computing features for Power System 
reliability. In the light of data center services, the average residential load without DR and with DR are depicted in Figure 15. However, it is cleared from the results and discussion that EVs are cheap controllable sources for DR. In this case study almost 10 (thousand MW) reduction (scheduling, shifting, and curtailment) is ensured using DR schemes. Moreover, this paper successfully achieved

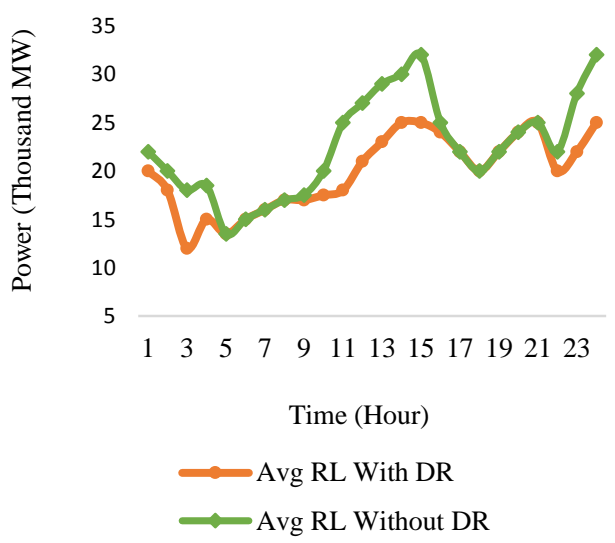

Figure 125: Average Residential Load Reduction Using DR Programs

the 50,000 EVs penetration for ISO California and declared that PEVs are the optimal solution to increase storage capacity for surplus power and plays important role in $\mathrm{V} 2 \mathrm{G}$ regulation in peak times.

\subsection{Impact of Ancillary Services of Data Center on DPS}

The importance and key contributions of the fast computational resources of the data center are already explained. Furthermore, the outcomes of data center's incorporation in proposed DPS are presented below:

- Computational Time: Computational time in power system prospective is the most important factor, particularly in job scheduling, resource allocation, and OPF convergence to satisfy the balance between supply and demand in power system and also avoid the system from threats and outages.

- Batch Job/task: In addition to large typical workload, data center is responsible to execute the power system jobs on first priority basis.

- In order to sustain optimal power consumption, data center divide the proposed DPS jobs in three categories: (a) Longest Job First (LJF), (b) Shortest Job First (SJF), and (c) Shortest Remaining Time First (SRTF) and the comparison of all scheduling techniques are presented in Figure 16.

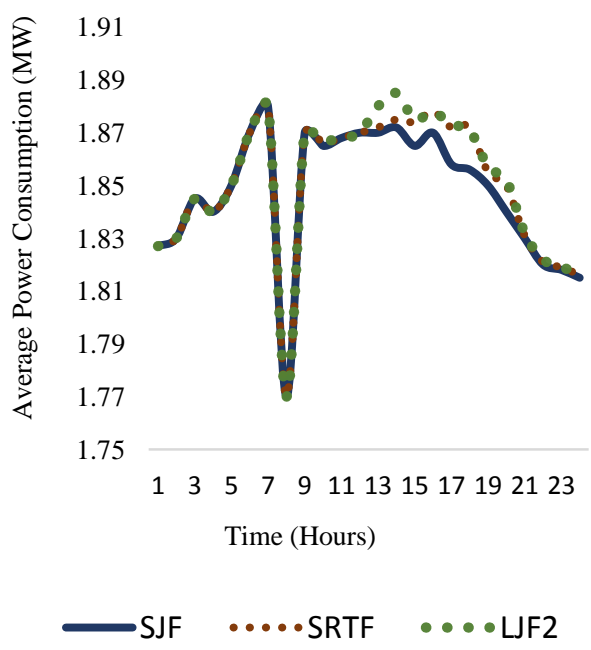

Figure 136: Cloud Computing DR Scheduling Techniques Implemented on DPS

In proposed DPS, it is noticed that in the morning hours and the time of low peak demand, the behavior of all schemes is similar while, the major difference is observed in the time of peak load demand.

\section{Conclusion}

This paper proposed the decision based optimization model for the proposed model comprising uncertain distributed RES integration, large scale PEV deployment and 
V2G regulation mode of PEVs. Moreover, three different behaviors of PEV's charging patterns are considered for simulation. In order to optimize power consumption, optimal scheduling strategy selection is performed by decision based algorithm. Later, the selected DR strategy is implemented on abovementioned three scenarios of charging patterns. For each scenario, individual results are calculated with significant load reduction, shifting, and shaping is envisioned. Moreover, cloud computing data centers offered fast computations services on prioritized basis to perform the power system jobs like DR programs, V2G regulation etc. In response, power system provides stable and economic power to data center which is the basic need of data center.

In future, the objective is to enhance this work by including Optimal Power Flow calculation using Newton Raphson method in the light of data center ancillary services. Furthermore, the simulations results will be performed in term of timespan, job preemptions, and makespan.

\section{References}

[1] Pierre Delforge, America's Data Centers Consuming and Wasting Growing Amounts of Energy, Natural Resources Defence Council, February 06, 2015.

[2] M. Mierau, R. Kohrs and C. Wittwer, "A distributed approach to the integration of electric vehicles into future smart grids," in 3rd IEEE PES International Conference and Exhibition on Innovative Smart Grid Technologies (ISGT Europe), Berlin, Germany, 2012.

[3] "International Energy Outlook 2016 With Projections to 2040," U.S. Energy Information Administration, May 2016.

[4] S. Raghavan and A. Khaligh, "Impact of plug-in hybrid electric vehicle charging on a distribution network in a Smart Grid environment," in IEEE PES Innovative Smart Grid Technologies (ISGT), , 2012.
[5] S. Han, S. Han and K. Sezaki, "Development of an Optimal Vehicle-to-Grid Aggregator for Frequency Regulation," IEEE Transactions on Smart Grid, vol. 1, no. 1, pp. 65-72, 2010.

[6] S. Deilami, A. Masoum, P. Moses and M. Masoum, "Real-Time Coordination of Plug-In Electric Vehicle Charging in Smart Grids to Minimize Power Losses and Improve Voltage Profile," IEEE Transactions on Smart grid, vol. 2, no. 3, pp. 456-467, 2011.

[7] N. Rotering and M. Ilic, "Optimal Charge Control of Plug-In Hybrid Electric Vehicles in Deregulated Electricity Markets," IEEE Transactions on Power Systems, vol. 26, no. 3, pp. 1021 - 1029, 2011.

[8] X. Bai and Wei Qiao, "Robust Optimization for Bidirectional Dispatch Coordination of Large-Scale V2G," IEEE Transactions on Smart Grid, vol. 6, no. 4, pp. 1944 - 1954, 2015

[9] T. Sousa, H. Morais, Z. Vale, P. Faria and J. Soares, "Intelligent Energy Resource Management Considering Vehicle-to-Grid: A Simulated Annealing Approach," IEEE Transactions on Smart Grid, vol. 3, no. 1, pp. 535-542, 2012.

[10] J. Soares, H. Morais, T. Sousa, Z. Vale and P. Faria, "Day-Ahead Resource Scheduling Including Demand Response for Electric Vehicles," IEEE Transactions on Smart Grid, vol. 4, no. 1, pp. 596-605, 2013.

[11] R. H. Katz, "tech titans building rooms," IEEE Spectrum, pp. 40-54, Feb. 2009.

[12] United States Environmental Protection Agency, "EPA report on server data center energy efficiency," Final Report to Congress, Aug. 2007.

[13] R. Azami and A. Fard, "Impact of demand response programs on system and nodal reliability of a deregulated power 
system," in IEEE International Conference on Sustainable Energy Technologies, 2008. ICSET 2008. , 2008.

[14] A. Tellidou and A. Bakirtzis, "Demand Response in Electricity Markets," in 15th International Conference on Intelligent System Applications to Power Systems, 2009. ISAP '09. , 2009.

[15] "Plug-in electric vehicles in the United States," [Online]. Available: https://en.wikipedia.org/wiki/Plugin_electric_vehicles_in_the_United_States. [Accessed 10 May 2016].

[16] M. H. Albadi and E. F. EI-Saadany, "Demand Response in Electricity Markets: An Overview," in IEEE Power Engineering Society General Meeting, 2007 , Tampa, FL, USA, 2007.

[17] M. Rahmani-Andebili, "Intelligent Implementing of TOU (Time-of-Use) Program by a GenCo," in 17 th Conference on Electrical Power Distribution Networks, Tehran, Iran, 2-3 May 2012.

[18] N. M. Carod, "A Cognitive Psychology Approach for Balancing Elicitation Goals," in Int. Conf. on Cognitive Informatics (ICCI'07), 2007.

[19] A. Chechich, "Cognitive-Driven Requirement Prioritaization : A case study," in Cognitive Informatics (ICCI'10), 2010.

[20] V. C. a. Y. Wang, "FROM COGNITIVE PSYCHOLOGY TO COGNITIVE INFORMATICS," in Second IEEE International Conference on Cognitive Informatics, 2003.

[21] R. M. F. a. J. SPURLIN, "Applications, Reliability and Validity of the Index of Learning Styles*," International Journal of Engineering Science, vol. 21, pp. 103-112, 2005
[22] L. RAMINGWONG, "A REVIEW OF REQUIREMENTS ENGINEERING PROCESSES PROBLEMS AND MODELS," International Journal of Engineering Science and Technology (IJEST), vol. 4, no. 6, pp. 2997-3002, 2012. 